\title{
Effects of Glutathions-S-transfsrases polymorphisms on carbamazepine plasmatic concentration, clearance and pharmacoresistance in Tunisian patients with epilepsy
}

\author{
B'chir Fatma ${ }^{1 *}$ and Saad Sagu ${ }^{2}$ \\ ${ }^{1}$ Laboratory of Natural Substances, National Institute of Research and Physical-Chemical Analysis (INRAP), Technopole Sidi, Thabet 2020, Tunisia \\ ${ }^{2}$ Metabolic Biophysics and Applied Pharmacology Laboratory, Department of Biophysics, Medicine Faculty of Sousse, 4002 Sousse, Tunisia
}

\begin{abstract}
Carbamazepine is one of the most prescribed anti-convulsive drugs used for the treatment of epileptic seizures. Large variability of carbamazepine daily maintenance doses, plasma concentrations, and treatment efficacy have been observed among patients treated with this agent. This variability may reflect functional consequences of genetic polymorphisms in genes encoding drug-metabolizing enzymes and/or targets. Glutathione-S-transferases enzymes are involved in the detoxification of several endogenous and exogenous substances. In this present study, we evaluated the effects of two glutathione-S-transferase polymorphisms, (GSTM1 and GSTT1) on carbamazepine plasma concentrations, carbamazepine clearance and carbamazepine response in 94 Tunisian patients with epilepsy, using a polymerase chain reaction. Mann-Whitney $U$ test and Odds ratio (ORs) was used for analyzing results. The study results demonstrated that individuals with the GSTM1 null genotype had significantly higher $\mathrm{CBZ}$ concentrations and $\mathrm{CBZ}$ clearance $(P=0.032 ; P=0.010$ respectively). These genotyping finding revealed that the absence of GSTM1 activity could be contributor factor for body toxicity among patients treated with CBZ. However there were no significant associations between all genotypes studies, GSTT1, GSTM1 and combined GSTT1-M1 and CBZ resistance epilepsy.
\end{abstract}

In conclusion, a lack of GSTM1 enzymes activities leads to drug plasmatic accumulation and its deficiency elimination which run to body toxicity.

\section{Introduction}

Epilepsy is a common neurological disorder, affecting approximately 1 to $2 \%$ of the population [1]. The majority of epileptic patients are successfully treated with anti-epileptic drugs. Carbamazepine (CBZ) is one of the most prescribed anti-convulsant drugs used for the treatment of epileptic seizures [2]. Large variability of CBZ daily maintenance doses, plasma concentrations, and treatment efficacy have been observed among patients treated with this agent [3]. This variability may reflect functional consequences of genetic polymorphisms in genes encoding drug-metabolizing enzymes and/or targets [4-7].

Carbamazepine is extensively metabolized in the liver, with less than $5 \%$ of an oral dose excreted unchanged in urine [8]. Carbamazepine is predominantly metabolized by CYP3A4, and partially by CYP2C8, to carbamazepine-10,11-epoxide. Carbamazepine-10,11-epoxide is subsequently transformed by microsomal Epoxide- Hydrolase ( $\mathrm{mEH}$ ) to the inactive carbamazepine-10,11-diol, which is finally excreted into the urine in free and conjugated forms [9]. Carbamazepine-10, 11-epoxide and carbamazepine-10,11-trans-diol are the primary $(\leq 60 \%)$ metabolites in urine $[10,11]$.

GSTs catalyze the conjugation of glutathione (GSH) with electrophiles, generally resulting in their detoxification and facilitated elimination $[12,13]$. The ability to conjugate electrophiles makes these enzymes critical in the detoxification of a wide range of epoxides and certain other agents, including therapeutic drugs, pesticides and dietary components $[14,15]$. Since some antiepileptic drugs are biotransformed to reactive oxides during their metabolism, GST is one of the key enzymes in the detoxification of these metabolites [16].

The present study was designed to comprehensively evaluate the effects of genetic polymorphisms of GSTM1, GSTT1 and combined GSTM1-T1 genes on CBZ plasma concentrations, CBZ clearance and CBZ response in 94 Tunisian patients with epilepsy. Especially, this is the first study to explore the effects of GSTs phase II enzymes on CBZ metabolism, and their relationship with CBZ drug resistance in Tunisian patients with epilepsy.

\section{Material and methods}

\section{Patients}

A total of 94 patients with epilepsy (41 males and 57 females) aged between 14 and 80 years were recruited from, the Neurology department of the University Hospital (CHU) Sahloul of Sousse (Tunisia), into the study. All patients were treated with CBZ monotherapy for a minimum of one year. This study was approved by the local ethnical committee. Informed consent was obtained from all participants.

Correspondence to: B'chir Fatma, Laboratory of Natural Substances, National Institute of Research and Physical-Chemical Analysis (INRAP), Technopole Sidi, Thabet 2020, Tunisia, E-mail: bchirfatma@hotmail.fr

Key words: carbamazepine, toxicity, epilepsy, PCR

Received: June 14, 2017; Accepted: July 07, 2017; Published: July 11, 2017 
Fatma B (2017) Effects of Glutathions-S-transfsrases polymorphisms on carbamazepine plasmatic concentration, clearance and pharmacoresistance in Tunisian patients with epilepsy

\section{HPLC analysis and Clearance, Carbamazepine plasma concentration measurements}

Blood samples were drawn from each patient after at least 1 week of continuous treatment with CBZ to ensure that patients' plasma drug concentrations were in steady state. Venous blood samples for CBZ concentration determination were collected from patients on empty stomach in the early morning. The therapeutic range of CBZ was 4 to $12 \mu \mathrm{g} / \mathrm{mL}$. Because of the differences in oral doses taken by the patients, steady-state plasma concentrations of CBZ were adjusted by dose and body weight of each patient.

After centrifugation at $3000 \mathrm{~g}$ for $20 \mathrm{~min}$ at $4^{\circ} \mathrm{C}$, plasma was then separated and stored at $-20^{\circ} \mathrm{C}$ until analysis. Plasma samples were analyzed by reversed phase HPLC (HPLC Agilent 1200), and using a Primidone as internal standard. A volume of $5 \mu \mathrm{l}$ of plasma samples was injected to the analytical Colum (C18 ODS, Agilent type) maintained at a temperature of $30^{\circ} \mathrm{C}$.

The assays were carried out using an isocratic mode with UV detection at $210 \mathrm{~nm}$. The mobile phase was consisting of proportions of acetonitrile, methanol and Potassium phosphate ( $\mathrm{pH}$ 6.09: $0.05 ; 18: 18: 64 \mathrm{~V} / \mathrm{V} / \mathrm{V}$ ) with a flow rate of $0.85 \mathrm{~mL} / \mathrm{min}$. Plasmatic CBZ concentrations were determinate by extrapolation to calibration curves previously established $(\mathrm{R}=0.997)$. The clearance of $\mathrm{CBZ}$ is calculated by the ratio of CBZ concentration on the daily dose of carbamazepine (D) serum levels of CBZ.

\section{Definition of drug resistance and response}

Drug resistance was defined as no change or $50 \%$ reduction in seizure frequency for at least 1 year, up to the date of the last followup visit, for patients on CBZ monotherapy. Drug response was defined as seizure freedom or a $\geq 50 \%$ reduction in seizure frequency for at least 1 year, up to the date of the last follow-up visit.

\section{Genotyping}

$5 \mathrm{ml}$ sample of blood was collected from each subject in a $7 \mathrm{ml} \mathrm{K} 3$ ETDA tube for genetic analysis. Genomic DNA was isolated from whole blood using the Wizard Genomic DNA Purification Kit (cat. ${ }^{*}$ A1120) (Promega, Madison, USA). The GSTM1/GSTT1 polymorphisms were detected using previously described Polymerase Chain Reaction (PCR)-based assays [17,18].

\section{Statistical analysis}

Statistical analysis was performed using SPSS software (Version18.0; SPSS Inc., IL, USA). The levels of CBZ and CBZ clearance of each genotype group were non-normally distributed variables, and thus compared using the nonparametric Mann-Whitney $U$ test. The level of significance was $5 \%(P<0.05)$. Deviation from Hardy-Weinberg equilibrium (HWE) was analyzed with the $\chi^{2}$ test.

Associations between response to CBZ treatment and GSTM1/ GSTT1 polymorphisms were measured as odds ratios (ORs) with $95 \%$ confidence intervals (CIs). A two-tailed $P$ value 0.05 was considered statistically significant.

\section{Results}

\section{Characteristics of the patients}

A total of 94 patients with epilepsy were recruited for this study and their characteristics are summarized in Table 1. CBZ doses, CBZ plasma concentrations, and adjusted CBZ plasma concentrations of the patients showed 8.18-, 4.3-, and 7.38-fold ranges, respectively, demonstrating
Table 1. Demographic characteristics of 94 patients with epilepsy

\begin{tabular}{|l|l|}
\hline Total number of patients studied & 94 \\
\hline Seizure type (partial/generalized) & $55 / 39$ \\
\hline Sex $(\mathrm{M} / \mathrm{F})$ & $40 / 54$ \\
\hline Age $($ years $)$ & $38.26 \pm 17$ \\
\hline Weight $(\mathrm{kg})$ & $63.3 \pm 7.6$ \\
\hline CBZ daily dose $(\mathrm{mg} / \mathrm{kg}$ per day) & $8.18 \pm 3.18$ \\
\hline CBZ plasma concentration $(\mu \mathrm{g} / \mathrm{mL})$ & $6.37 \pm 1.97$ \\
\hline Adjusted CBZ plasma concentration $(\mu \mathrm{g} / \mathrm{mL}$ per $\mathrm{mg} / \mathrm{kg})$ & $1.1 \pm 0.4$ \\
\hline CBZ responsiveness/resistance & $76 / 18$ \\
\hline
\end{tabular}

large interindividual variations in CBZ pharmacokinetics. After 1 year of CBZ treatment, less than the third of patients were drug resistant in our study.

\section{Relationships between GSTM1/T1 polymorphisms and plasma carbamazepine concentrations}

The relationship between, GSTM1, GSTT1 and combined GSTM1-T1 polymorphisms and CBZ plasma concentration are summarized in Table 2.

No significant associations were detected between GSTM1 null genotype, combined GSTM1-T1 and CBZ concentration. However, statistical analyses revealed significant association between adjusted CBZ concentrations and GSTT1 null genotype $(P=0.032)$. Patients with the null GSTT1 genotype had significantly higher CBZ concentrations than patients with GSTT1 active enzyme.

\section{Relationships between GSTM1/T1 polymorphisms and carbamazepine clearance}

Table 3 illustrates the correlation between GSTM1, GSTT1 and combined GSTM1-T1 polymorphisms and CBZ clearance. There is no association between GSTT1 null genotype, combined GSTT1-M1 polymorphisms and CBZ clearance in our study.

A statistically significant association was found only between GSTM1 null genotype and CBZ clearance $(P=0.010)$. Patients with GSTM1 null genotype have the higher CBZ clearance (99.28 \pm 62.63$)$ than patients with GSTM1 active genotype $(92.11 \pm 29.34)$.

Patients with combined GSTM1-T1 positif genotype have tendency to eliminate CBZ rapidly than patients with combined GSTM1-T1 null genotype, however this difference was not statistically significant $(P=0.08)$.

\section{Relationships between GSTM1/T1 polymorphisms and carbamazepine resistance}

There were no significant differences between GSTM1/T1 polymorphisms and CBZ resistance (Table 4). In spite of this result genotype frequencies of GSTM1, GSTT1 and combined GSTM1-T1 were higher in patients CBZ-responsive than CBZ-resistant patients, but these differences were not statically significant.

Combined GSTM1-T1 null genotypes had a tendency to increase drug resistance in epilepsy $(O R=2.55)$, although not statistically significantly (Table 4).

\section{Discussion}

In this study we have examined the impacts of two type of glutathione-S transferases gene GSTM1 and GSTT1 polymorphisms on CBZ pharmacokinetic parameters including the carbamazepine plasma concentrations and carbamazepine clearance. We have also 
Fatma B (2017) Effects of Glutathions-S-transfsrases polymorphisms on carbamazepine plasmatic concentration, clearance and pharmacoresistance in Tunisian patients with epilepsy

Table 2. Association between GSTM1/GSTT1 polymorphisms and CBZ adjusted concentrations

\begin{tabular}{|c|c|c|c|c|}
\hline Gene & Genotype & $\begin{array}{c}\text { Number } \\
\text { of patients } \\
(n=94)\end{array}$ & $\begin{array}{c}\mathrm{CBZ} \\
\text { concentration }\end{array}$ & P value \\
\hline \multirow{2}{*}{ GSTT1 } & Null allele (-/-) & 21 & $7.47 \pm 2.65$ & \multirow{2}{*}{0.032} \\
\hline & Active allele $(+/+)$ or $(+/-)$ & 73 & $6.096 \pm 2.58$ & \\
\hline \multirow{2}{*}{ GSTM1 } & Null allele (-/-) & 72 & $6.42 \pm 2.41$ & \multirow{2}{*}{0.74} \\
\hline & Active allele $(+/+)$ or $(+/-)$ & 22 & $6.189 \pm 3$ & \\
\hline \multirow{2}{*}{$\begin{array}{l}\text { Combined } \\
\text { GSTM1-T1 }\end{array}$} & GSTM1/T1(-/-) & 15 & $7.79 \pm 2.92$ & \multirow{2}{*}{0.16} \\
\hline & GSTM1/T1(+/+) & 16 & $6.18 \pm 3.32$ & \\
\hline
\end{tabular}

Table 3. Association between GSTM1/T1 polymorphisms and CBZ clearance

\begin{tabular}{|c|c|c|c|c|}
\hline Gene & Genotype & $\begin{array}{c}\text { Number } \\
\text { of patients } \\
(n=94)\end{array}$ & CBZ clearance & $P$ value \\
\hline \multirow{2}{*}{ GSTT1 } & Null allele (-/-) & 21 & $96.356 \pm 35.558$ & \multirow{2}{*}{0.48} \\
\hline & Active allele $(+/+)$ or $(+/-)$ & 73 & $102.5 \pm 91.95$ & \\
\hline \multirow{2}{*}{ GSTM1 } & Null allele (-/-) & 72 & $92.11 \pm 29.34$ & \multirow{2}{*}{0.01} \\
\hline & Active allele $(+/+)$ or $(+/-)$ & 22 & $99.28 \pm 62.63$ & \\
\hline \multirow{2}{*}{$\begin{array}{l}\text { Combined } \\
\text { GSTM1-T1 }\end{array}$} & GSTM1/T1(-/-) & 15 & $95.52 \pm 33.10$ & \multirow{2}{*}{0.08} \\
\hline & GSTM1/T1(+/+) & 16 & $99.75 \pm 66.52$ & \\
\hline
\end{tabular}

Table 4. Genotypes frequencies of GSTM1/T1 polymorphisms in CBZ-resistant and CBZresponsive in patients with epilepsy

\begin{tabular}{|c|c|c|c|c|c|}
\hline \multirow[b]{2}{*}{ Gene } & \multirow[b]{2}{*}{ Genotype } & \multicolumn{2}{|c|}{ Frequency } & \multirow[b]{2}{*}{ OR } & \multirow[b]{2}{*}{$\begin{array}{c}P \\
\text { value }\end{array}$} \\
\hline & & $\begin{array}{c}\text { CBZ-resistant } \\
\text { epilepsy } \\
\text { n } \%\end{array}$ & $\begin{array}{c}\text { CBZ- } \\
\text { responsive } \\
\text { epilepsy } \\
\text { n \% }\end{array}$ & & \\
\hline \multirow{2}{*}{ GSTT1 } & $\begin{array}{l}\text { Null allele }(-/-) \\
n=21\end{array}$ & $05(23.81)$ & $16(76.19)$ & \multirow{2}{*}{$\begin{array}{c}1.44 \\
(0.38- \\
5.26)\end{array}$} & \multirow{2}{*}{0.53} \\
\hline & $\begin{array}{c}\text { Active allele }(+/+) \text { or }(+/-) \\
n=73\end{array}$ & $13(17.81)$ & $60(82.19)$ & & \\
\hline \multirow{2}{*}{ GSTM1 } & $\begin{array}{l}\text { Null allele (-/-) } \\
n=72\end{array}$ & $15(20.83)$ & $57(79.16)$ & \multirow{2}{*}{$\begin{array}{c}1.67 \\
(0.39- \\
8.16)\end{array}$} & \multirow{2}{*}{0.55} \\
\hline & $\begin{array}{l}\text { Active allele }(+/+) \text { or }(+/-) \\
\mathrm{n}=22\end{array}$ & $3(13.63)$ & $19(90.47)$ & & \\
\hline \multirow{2}{*}{$\begin{array}{l}\text { Combined } \\
\text { GSTM1-T1 }\end{array}$} & $\begin{array}{l}\text { GSTM1-T1(-/-) } \\
\mathrm{n}=15\end{array}$ & $4(26.66)$ & $11(73.33)$ & \multirow{2}{*}{$\begin{array}{l}2.55 \\
(0.30- \\
25.11)\end{array}$} & \multirow{2}{*}{0.39} \\
\hline & $\begin{array}{c}\operatorname{GSTM} 1(+/+) \\
\mathrm{n}=16\end{array}$ & $2(12.5)$ & $14(87.5)$ & & \\
\hline
\end{tabular}

studied the effect of these polymorphisms on interindividual variation of CBZ drug response among Tunisian population.

Our results demonstrated that Tunisian patients with GSTT1 null genotypes had significantly higher CBZ plasmatic concentration and patients with GSTM1 null genotypes were associated with lower clearance values. This data revealed that both GSTT1 and GSTM1 enzymes are implicated in the metabolism of CBZ and mainly in the detoxification of this drug and its elimination. So a lack of GSTs enzymes activities leads to drug plasmatic accumulation and its deficiency elimination which run to body toxicity mainly kidney and hepatotoxicity.

Our results are in consistent with the recent association studies reporting that genetically determinate deficiency in GSTs might be a risk factor for hepatotoxicity among patients treated with CBZ [19].

There is a large inter-individual variability for GSTM1 and GSTT1 due to the presence of the null (zero activity) genotype, which is common in all populations studied [16]. The GSTM1 and GSTT1 genotypes have also been studied across wide variety of populations. The GSTM1 null genotype is common, with frequencies of $40-60 \%$ in Caucasians and Asians, and $20-25 \%$ in African Americans [16]. The
GSTT1 null genotypes less frequent than the GSTM1 null genotype in Caucasians (18\%) but has a similar frequency to the GSTM1 null genotype in Asian groups (generally ranging from 40-60\%) and in African Americans (22\%) [16].

So, the lack of GSTs enzymes activities may be risk factor for body toxicity among patients treated with CBZ. Therefore, a preventive analysis should be necessary before any treatment with CBZ among patient with epilepsy.

Our results also suggest that combined GSTM1-T1 null genotypes may be associated with increased risk of CBZ resistance in Tunisian patients, the odds ratios was greater than 2.0, though this value was not statistically significant.

The lack of significant associations between the GSTT1 and GSTM1 genotypes and CBZ resistance in our study may be attributed to several factors. First, the sample size of our study may be not large enough to render sufficient power to detect a significant association. Second, there are multiple genes that could theoretically affect CBZ plasma levels and pharmacoresistance in epilepsy, including CBZ-metabolizing enzymes, CYP3A4/5 and CYP2C8, and/or targets of CBZ, sodium channels SCN1A and SCN2A [20-22].

In fact several studies have investigated the relationships between polymorphisms of CBZ-metabolizing Enzymes [23,24], brain receptors $[20,22]$ and interindividual variations in pharmacokinetics parameters and response to drug. All the results are controversial.

The Discrepancies in the results of different studies may be attributed to ethnic differences in the frequencies of enzymes genotypes more over this discrepancies maybe also attributed to the kind of studies directed which one or two enzymes polymorphisms. There is no study which takes in consideration the contributions of all enzymes and receptors polymorphisms of the CBZ pathway.

In summary, the present work was the first study which investigates the association between the polymorphisms of phases II enzymes GSTs and interindividual variation in CBZ treatment and its pharmacokinetics parameters.

Our results indicate that patients with the null GSTT1 genotype had significantly higher CBZ concentrations than patients with GSTT1 active enzyme, and Patients with GSTM1 null genotype have the higher CBZ clearance than patients with GSTM1 active genotype. However, there were no significant associations between all genotypes studies, gstt1, GSTM1 and combined GSTT1-M1 and CBZ resistance epilepsy. This may be attributed to small sample size, multiple gene contributions, and ethnic differences. A study with a larger cohort of patients and takes in consideration a combination of large range of genes is warranted.

\section{References}

1. Saruwatari J, Ishitsu T, Nakagawa K (2010) Update on the Genetic Polymorphisms of Drug-Metabolizing Enzymes in Antiepileptic Drug Therapy. Pharmaceuticals (Basel) 3: 2709-2732. [Crossref]

2. Yun W, Zhang F, Hu C, Luo X, Xue P, et al. (2013) Effects of EPHX1, SCN1A and CYP3A4genetic polymorphisms on plasmacarbamazepine concentrations and pharmacoresistance in Chinese patients with epilepsy. Epilepsy Research 107: 231-237.

3. Kwan P, Brodie MJ (2001) Effectiveness of first antiepileptic drug. Epilepsia 42: 1255 1260. [Crossref]

4. Sisodiya SM, Marini C (2009) Genetics of antiepileptic drug resistance. Curr Opin Neurol 22: 150-156. [Crossref]

5. Kaneko S, Yoshida S, Kanai K, Yasui-Furukori N, Iwasa H (2008) Development of individualized medicine for epilepsy based on genetic information. Expert Rev Clin Pharmacol 1(5): 661-681. 
Fatma B (2017) Effects of Glutathions-S-transfsrases polymorphisms on carbamazepine plasmatic concentration, clearance and pharmacoresistance in Tunisian patients with epilepsy

6. Löscher W, Klotz U, Zimprich F, Schmidt D (2009) The clinical impact of pharmacogenetics on the treatment of epilepsy. Epilepsia 50: 1-23. [Crossref]

7. Kasperaviciute D, Sisodiya SM (2009) Epilepsy pharmacogenetics. Pharmacogenomics 10(5):817-36

8. Eichelbaum M, Tomson T, Tybring G, Bertilsson L (1985) Carbamazepine metabolism in man. Induction and pharmacogenetic aspects. Clin Pharmacokinet 10(1): 80-90.

9. Tomson T, Tybring G, Bertilsson L (1983) Single-dose kinetics and metabolism of carbamazepine-10,11-epoxide. Clin Pharmacol Ther 33: 58-65. [Crossref]

10. Kerr BM, Thummel KE, Wurden CJ, Klein SM, Kroetz DL, et al. (1994) Human liver carbamazepine metabolism. Role of CYP3A4 and CYP2C8 in 10,11-epoxide formation. Biochem Pharmacol 47: 1969-1979. [Crossref]

11. Kang P, Liao M, Wester MR, Leeder JS, Pearce RE, et al. (2008) CYP3A4-Mediated carbamazepine (CBZ) metabolism: formation of a covalent CBZ-CYP3A4 adduct and alteration of the enzyme kinetic profile. Drug Metab Dispos 36(3): 490-499.

12. Hayes JD, Strange RC (2000) Glutathione S-transferase polymorphisms and their biological consequences. Pharmacology 61(3): 154-166.

13. Hayes JD, Flanagan JU, Jowsey IR (2005) Glutathione transferases. Annu Rev Pharmacol Toxicol 45: 51-88. [Crossref]

14. Bolt HM, Thier R (2006) Relevance of the deletion polymorphisms of the glutathione S-transferases GSTT1 and GSTM1 in pharmacology and toxicology. Curr Drug Metab 7: 613-628. [Crossref]

15. Reszka E, Wasowicz W, Gromadzinska J (2006) Genetic polymorphism of xenobiotic metabolizing enzymes, diet and cancer susceptibility. Br J Nutr 96: 609-619.
16. Ginsberg G, Smolenski S, Hattis D, Guyton KZ, Johns DO, et al. (2009) Genetic Polymorphism in Glutathione Transferases (GST): Population distribution of GSTM1, T1, and P1conjugating activity. J Toxicol Environ Health B Crit Rev 12: 389-439.

17. Chbili C, B'chir F, Fredj MB, Saguem B, Amor SB, et al. (2014) Effects of glutathione S-transferase M1 andT1 deletions on epilepsy risk among aTunisian population. Epilepsy Research 108: 1168-1173.

18. Oke B, Akbas F, Aydin M, Berkkan H (1998) GSTT1 null genotype frequency in a Turkish population. Arch Toxicol 72: 454-455. [Crossref]

19. Ueda K, Ishitsu T, Seo T, Ueda N, Murata T, et al. (2007) Glutathione S-transferase M1 null genotype as a risk factor for carbamazepine-induced mild hepatotoxicity. Pharmacogenomics 8(5): 435-442.

20. Yuna W, Zhanga F, Huc C, Luoc X, Xuea P, et al. (2013) Effects of EPHX1, SCN1A and CYP3A4 genetic polymorphisms on plasmacarbamazepine concentrations and pharmacoresistance in Chinese patientswith epilepsy. Epilepsy Research 107: 231-237

21. Tate SK, Singh R, Hung CC, Tai JJ, Depondt C, et al. (2006) A common polymorphism in the SCN1A gene associates with phenytoin serum levels at maintenance dose. Pharmacogenet Genomics 16: 721-726. [Crossref]

22. Hung CC, Chang WL, Ho JL, Tai JJ, Hsieh TJ, et al. (2012) Association of polymorphisms in EPHX1, UGT2B7, ABCB1, ABCC2, SCN1A and SCN2Agenes with carbamazepine therapy optimization. Pharmacogenomics 13: 159-169.

23. Park PW, Seo YH, Ahn JY, Kim KA, Park JY (2009) Effect of CYP3A5*3 genotype on serum carbamazepine concentrations at steady-state in Korean epileptic patients. $J$ Clin Pharm Ther 34: 569-574

24. Nakajima Y, Saito Y, Shiseki K, Fukushima-Uesaka H, Hasegawa R, et al. (2005) Haplotype structures of EPHX1 and their effects on the metabolism of carbamazepine10,11-epoxide in Japanese epileptic patients. Eur J Clin Pharmacol 61: 25-34.

Copyright: $($ C2017 Fatma B. This is an open-access article distributed under the terms of the Creative Commons Attribution License, which permits unrestricted use, distribution, and reproduction in any medium, provided the original author and source are credited. 